\title{
Multiples for Valuation Estimates of Companies in the Technology Sector of Emerging Markets
}

\author{
Oleg Nikolayevich Salmanov ${ }^{1}$, Natalia Vladimirovna Babina ${ }^{1}$, Svetlana Viktorovna Bashirova ${ }^{1}$ \& Marina \\ Viktorovna Samoshkina ${ }^{1}$ \\ ${ }^{1}$ The Finance and Technology Academy, the city of Korolev, Russian Federation \\ Correspondence: Oleg Nikolayevich Salmanov, Gagarina Street, 42, Korolev, Moscow Region, 141070, Russian \\ Federation._E-mail: olegsalmanov@yandex.ru;_babina@fta-mo.ru; bashirova5959@mail.ru; \\ mvsam97@yandex.ru
}

Received: November 27, 2014 Accepted: December 10, $2014 \quad$ Online Published: March 20, 2015

doi:10.5539/ass.v11n8p253

URL: http://dx.doi.org/10.5539/ass.v11n8p253

\begin{abstract}
Market multiples are a tool for estimation corporate value. These tools are expressed as temporal dynamics and differences in the markets, sectors, industries, firms. Despite their great practical application, a number of problems remains which continue to be debated. This article examines the explanatory power of multiples, and makes a comparison of multiples for the technology sector with the market as a whole, and multiples for the technology sector of Emerging Markets are established within the ranking, most fully explaining the value of stocks using an approach that ensures mitigating the differences in multiples from basic variables.
\end{abstract}

Keywords: valuation, valuation multiples, ratio analysis

JEL: G12, M41

\section{Introduction}

Valuation multiples are widely used for comparative valuation of company assets. However, despite the ease of use, a false investment decision can be easily made. In this regard, an ongoing debate about the principles and certain aspects of the multiple applications continues in the financial literature. Issues on which research continues and the understanding of this problem extends are: what factors determine the level of multiples; which multiples achieve better results; valuation accuracy of multipliers; how to select comparable firms; how differences in the variables determining the multiple are mitigated, and which multiples are better for each type of industry.

Many studies focus on the question of which revenue multiples achieve the best results and the valuation accuracy of various types of multiples. Liu, Nissim, and Thomas (2002) examined the properties of valuation multiples of an entire list of multiples and showed that the historical earnings are valuated in the second place after forward earnings, cash flow and book value of equity are on the third, and multiples based on earnings show worse results. Liu, Nissim, and Thomas in the study (2007) expanded the analysis and found that the multiples based on earnings have an advantage compared to multiples based on operating cash flow.

Lie \& Lie (2002) examined the accuracy of a common list of multiples for firms within the database of North America. They reported that the multiples that use the indicators of equity and invested capital tend to outweigh the revenue-based multiples.

Studies such as Cheng and McNamara (2000), Yee (2004) and Yoo (2006) have focus on linear combinations of differences of estimations of the values and offer averaging (valuation estimates) in order to improve the level of the valuation.

In particular, these studies have found that that book value and earnings multiples lead to a reduction of errors in comparison with any multiple, on average. Yee (2008) suggests Bayesian framework for combining valuation estimates.

Using a different approach, Bhojraj \& Lee (2002) show that the accuracy of forecasting of multiples can be improved by closely selected set of comparable firms. They believe that their method of selecting comparable firms provides improved accuracy compared with the selection of comparable firms on the basis of industry. 
Their approach includes two components: (1) regression analysis of multiples using the standard value-drivers as independent variables, and (2) the selection of closely comparable firms on the basis of their valuated relations.

According to the European data, Schreiner \& Spremann (2007) examined the accuracy of various multiples. They argue that the equity valuation multiples $(\mathrm{P} / \mathrm{E}, \mathrm{P} / \mathrm{BV})$ outweigh in accuracy the enterprise value multiples (EV) - the EV/EBITDA and EV/EBIT multiples.

Cheng and McNamara (2000) suggested to combine the P/E and P/BV multiples for the most accurate valuation results.

Which factor determines the level of valuation multiples - this issue continues to be in the focus of attention of many researchers. Among them, Cheng \& McNamara (2000) reported that the use of earnings per share - the relevant criterion for selecting the appropriate P/E and P/BV multiples. Dittmann and Weiner (2005) recommend the use of return of assets (ROA) as a selection criterion for the EV/EBIT multiples in the similar study.

Penman \& Zhang (2006) analyzed the effect of sustainable earnings on the P/E multiple. The authors shown in their tests that the analysis reliably identifies unsustainable earnings, and also explains the spatial differences in the $\mathrm{P} / \mathrm{E}$ ratios.

Damodaran (2012) gave a significant role to multiples in his comprehensive book. The author proceeded from the assumption that the multiples are determined by fundamental factors arising from the discounted cash flow model - indicators of growth, risk and the potential to create cash flows. These figures are varied for different multiples. The author opens the question of how changes in basic variables affect the multiple, as well as the question of the comparability of the multiples on the market, in the industry. Damodaran rightly believes that one of the best opportunities to mitigate the differences in risk, growth and cash flow indicators is regression of multiples on these basic variables.

Such regressions change over time, markets and industries, and require constant analysis.

Easton (2004) analyzes the P/E and PEG ratios. The author draws attention to the fact that the PEG ratio takes into account differences in short-term growth rates in earnings and implicitly assumes that short-term growth forecast also captures the distant future. Easton provides means of the simultaneous valuation of expected rate of return and speed of change in the abnormal growth in earnings within a short forecast horizon, and thus clarifies the PEG ratio.

Cooper \& Cordeiro (2008) study the issue of the number of comparable firms for evaluation with multiples and accuracy of valuation changes. The authors conclude that ten closely comparable firms are accurate measure of firms in the industry, on average. According to the authors, the relative accuracy of the valuation based on a small number of comparable firms depends heavily on the similarities of comparable firms with the objective firm.

Henschke \& Homburg (2009) examine the problem of the differences between firms and impact on valuations based on multiples. They believe that the differences between firms lead to systematic errors in the value estimates of different multiples. The authors find that these errors can be predicted very accurately by comparing the financial ratios of the objective firm with its financial ratios of comparable groups.

Holthausen \& Zmijewski (2012) analyze the evaluation process for the selecting companies that are really comparable with the objective firm. The authors note that the aim of valuating comparability is to align the relevant value drivers - especially risk and growth - of the comparable companies with those of the company being valued. In this article, the authors examine the relevant value drivers for the EBIT and EBITDA multiples. They show that, in addition to the risk and growth, analysts applying market valuation multiples should take into account the differences in variables such as cost structure, working capital and capital expenditures. They show that, in addition to risk and growth, analysts doing market multiple valuations need to take into account differences in variables such as cost structure, working capital, and capital expenditure requirements.

Harbula (2009) analyses market multiples as a tool to valuate assets. He examines the accuracy and the main drivers of valuation multiples and explains their relative and absolute level. In particular, he believes that the value multiples EV/EBITDA, EV/EBIT are the most relevant multiples for the technology sector of industry, for them the valuation error (mean/median) is $21 \% / 18 \%$.

Fernandez (2013) shows that although P/E and EV/EBITDA seem to be the most popular multiples, but it is also true that, depending on the type of industry specific multiples are more appropriate than others. The author gives the most commonly used multiples in various industries. In the technology sector (Software, equipment \& semiconductors) such multiples are PE and relative PE. Fernandez found that the multiples are almost always 
have a wide dispersion, thus the valuations made using multiples can be very controversial. The author notes that the multiples are useful in the second stage of valuation, when after the valuation a different method is used, comparison with multiples of comparable firms allows measuring the valuation and identify the differences between the estimated firm and firms with which it is compared.

Gaio S. (2009) researched on differences of earnings levels depending on the characteristics of firms and countries. He finds that the company, country and industry factors have explanatory power. The author points out that today firm and industry characteristics explain much more of the variations in earnings quality ranking than country characteristics. Even though that particular country features are important, they are not the primary source of change according to Gaio. Firm characteristics play a crucial role in explaining firm-level earnings quality at the different cross-section macroeconomic conditions. That is, according to the author, country characteristics have priority in the explanatory power of firm characteristics in less economically developed countries, and vice versa, the firm characteristics have priority in more economically developed countries.

The authors show that with accounting and financial globalization in the late 1990s, country characteristics have lost a bit of ability to explain changes in earnings worldwide. In the earlier 1990s, country characteristics were dominant. In more recent times, firm characteristics became the major determinant of the level of earnings in the world.

Foster \& Kasznik (2011) studies the relative importance of the country and the specific factors of a particular industry to explain the differences in multiples. The authors believe that company-specific factors are dominant in explaining cross-sectional differences in valuation, country and industry factors have greater explanatory power over them. The authors note that the expansion of the fields of study to the global stage allows quantitative install (and test hypotheses) the importance of the factors for which there are more changes in the country sample than in a single country sample. The authors believe that in explaining cross-sectional differences in factors of firms, countries, industries have the ability to assess the relationship of three actions: revenue, earnings, and equity book value multiples.

An \& Bhojraj (2010) studied the role of country, industry, and valuation components. The authors analyze the Book-to-Market and Earnings-to-Price ratios in country, industry, and firm. According to the authors, country membership has significantly more impact on these valuation ratios compared to industry membership. The authors find that special (idiosyncratic) and country components are the main drivers of the valuation ratios. However, the importance of country varies in different countries. Such a difference the authors explain by the level of country governance, market efficiency, capital openness, firm illiquidity, and information uncertainty.

Country and industry effects are most suitable to explain the variation in valuation of the market and the book value of equity. Industry factors are typically stronger for income variables. According to Foster \& Kasznik (2011), the difference in the country and industry weight contributions may be due to differences in time-period, country and industry composition, and industry definition. This research study and Foster (2011) and An (2010) conclude that both country and industry factors are individually significant in international equity valuation.

In general, the existing literature reveals the important role of these country-specific variables in the country in a variety of research contexts.

Damodaran A. (2009) proposed the systematic basis for valuing emerging markets companies. The author notes that in many small Emerging Markets, a few companies will be taken as comparable for inclusion in the group of firms in the same market and in the same business. At the same time, relative valuation based on small sample size is precarious, simply because judgments are made on limited data. The use of valuation in a particular sector of industry is a method of increasing the sample of comparable firms.

The author believes that even when we can get a large number of firms into comparison, there can be big differences between these firms on risk and growth characteristics that can make misleading comparisons. A. Damodaran believes that regression analysis can be used to control differences in the case of Emerging Market companies. In addition, it is necessary to take into account the liquidity, as in many Emerging Markets, only the top number of stocks are liquid and widely traded and small companies are often illiquid. And therefore A. Damodaran proposes to control differences in liquidity (using the trading volume or offer spread as trusted persons) in the comparison between firms.

\section{Methodology}

In this study, the aim is to set the most appropriate multiples for valuation estimates of companies in the technology sector of Emerging Markets. It is supposed to match the whole list of multiples for Emerging Stock Markets and technology sector. The technology sector includes companies of the following industries: Computer 
Services; Computer Software; Computers/Peripherals; Electronics; Electronics (Consumer \& Office); Semiconductor; Semiconductor Equipment.

It is known that the same multiples for different markets, industries and companies do not exist. Differences in multiples result from differences in determining variables. The common approach for performing valuation of multiples is to select a group of comparable firms, calculate of the average value of the multiple for the group and adjust subjectively the resulting value to mitigate the differences between the estimated and comparable companies. However, this procedure does not remove the differences in the basic variables with the comparable group of firms. An alternative approach is known. It lies in the regression approach, which may explain a significant part of the difference in the regression between the multiples of different companies in a sector of industry. Obviously, the regression equation may be used for evaluating the values of the multiples for each firm of the sector. Moreover, these values can be compared with the actual multiples to make judgments about the overvalued or undervalued stocks.

In this study regression analysis is used to mitigate the differences between variables. Indicators of descriptive statistics will act as the criteria for multiple accuracy: the standard error, standard deviation and coefficient of variation. The properties of the established regression equations will be the criteria of the most appropriate multiples. It is supposed to compare multiples on maximum explained variance corresponding the regression equations, that is on the coefficient of determination with significant t-statistics and F-statistics tests. Estimated values of the multiples obtained by regression equations will be compared with the actual values of the multiples for making decisions about overvalued or undervalued stocks.

The data were taken at 01.01.2013. The data source is Value Line Data, Capital IQ and Bloomberg, taken from the website of Damodaran (April, 2014). Companies for which there was no information and emissions - values outside the possible outliers were removed when preparing the samples.

\section{Empirical Results}

Descriptive statistics for the sample multiples of Emerging Stock Markets (the number of observations is 1737) is shown in Table 1. It is ranked by the coefficient of variation - relation of the mean value to the standard deviation.

Table 1. Statistics for the sample multiples of all emerging markets, ranked by coefficient of variation

\begin{tabular}{llllllll}
\hline & Mean & Standard error & Median & Standard deviation & $\min$ & $\max$ & $\begin{array}{l}\text { Coefficient of } \\
\text { variation, \% }\end{array}$ \\
\hline Forward PE & 17.67 & 0.28 & 15 & 11.81 & 0.38 & 138.8 & 66.8 \\
EV/EBITDA & 16.31 & 0.38 & 12 & 15.68 & -1.11 & 240.5 & 96.2 \\
Current PE & 25.26 & 0.61 & 18.02 & 25.49 & 0.93 & 279.0 & 100.9 \\
EV/Sales & 3.40 & 0.09 & 2.21 & 3.86 & -0.25 & 36.0 & 113.5 \\
PS & 3.07 & 0.09 & 1.89 & 3.79 & 0.06 & 36.1 & 123.2 \\
PBV & 3.17 & 0.10 & 2.08 & 4.15 & 0.16 & 88.5 & 130.7 \\
EV/Invested & 3.81 & 0.22 & 2 & 9.03 & -0.69 & 288.0 & 237.1 \\
Capital & 24.00 & 2.03 & 14.95 & 84.49 & -1.29 & 2767.9 & 352.1 \\
EV/EBIT & 2.11 & 0.33 & 1.16 & 13.91 & 0.02 & 555.8 & 660.0 \\
PEG & & & & & & & \\
\hline
\end{tabular}

Forward P/E, EV/EBITDA, Current P/E multiples have the lowest coefficient of variation, and PEG, EV/EBIT, EV/Invested Capital multiples have the highest coefficient of variation.

Descriptive statistics of multiples in the technology sector of Emerging Markets is given in Table 2 (the number of observations is 173).

In the technology sector. Forward P/E, PBV, Current P/E multiples have the lowest coefficient of variation, and EV/Invested Capital, PS, EV/Sales multiples have the highest coefficient of variation.

Current PE - 25.3 and then EV/EBITDA - 20.271have the largest standard deviation values. PEG - 2.07, then PBV - 2.64, and EV/Sales - 4.75 have the smallest standard deviation values.

For regression analysis, as covariates were chosen basic variables which characterize the growth, risk and cash 
flow which in turn were analyzed by t-statistics. The following notation are used in the formulas: $\mathrm{g}$ - Expected growth rate in EPS next 5 years; PayR - Payout ratio; ROE - return on equity; beta - risk indicator (the slope coefficient in the CAPM model); Net Margin - Net Profit Margin; DebtR - Market Debt to capital ratio; ROIC return on invested capital; OperMarg - Pre-tax Operating Margin; TaxRate - Effective Tax Rate.

Table 2. Statistics of sample multiples in the technology sector of emerging markets, ranked by coefficient of variation

\begin{tabular}{llllllll}
\hline & Mean & Standard error & Median & Standard deviation & $\min$ & $\max$ & $\begin{array}{l}\text { Coefficient of } \\
\text { variation, \% }\end{array}$ \\
\hline Forward PE & 18.95 & 1.13 & 14.34 & 14.86 & 1.55 & 115.4 & 78.4 \\
PBV & 3.35 & 0.20 & 2.47 & 2.64 & 0.31 & 14.2 & 78.9 \\
Current PE & 28.49 & 1.92 & 18.33 & 25.31 & 3.53 & 147.7 & 88.8 \\
EV/EBITDA & 19.38 & 1.54 & 11.56 & 20.27 & 2.04 & 140.1 & 104.6 \\
EV/EBIT & 24.27 & 2.07 & 14.52 & 27.17 & 3.02 & 175.6 & 111.9 \\
PEG & 1.69 & 0.16 & 1.23 & 2.07 & 0.25 & 21.4 & 122.6 \\
EV/Sales & 3.81 & 0.36 & 1.95 & 4.75 & 0.09 & 27.3 & 124.4 \\
PS & 3.97 & 0.38 & 1.95 & 5.02 & 0.08 & 29.4 & 126.3 \\
EV/Invested & 5.00 & 0.50 & 3.06 & 6.63 & 0.38 & 57.0 & 132.5 \\
Capital & & & & & & &
\end{tabular}

The following results were obtained as a result of the regression analysis. First, throughout the whole Emerging Stock Markets:

Multiple (price/earnings) - $\mathrm{P} / \mathrm{E}$. The coefficient of determination $-\mathrm{R}^{2}=0.47$. The values of t-statistics are given in following expressions.

$$
\begin{gathered}
P E=17.56-4.59 \beta+57.56 g+1.83 \text { PayR } \\
\text { (14.58) (-6.35) (21.38) }
\end{gathered}
$$

Forward PE. $\mathrm{R}^{2}=0.29$.

$$
\begin{gathered}
P E_{F}=18.31-3.14 \beta+10.69 g+1.83 \text { PayR } \\
(29.58)(-8.44) \quad(7.73) \quad(5.53)
\end{gathered}
$$

PEG multiple. $\mathrm{R}^{2}=0.508$.

$$
\begin{gathered}
P E G=-1.34+0.143 \text { PayR }-1.84 \ln (g)-0.287 \beta \\
(-7.29) \quad(1.997) \quad(-23.95) \quad(-3.53)
\end{gathered}
$$

"Price/Book" PBV multiple. $\mathrm{R}^{2}=0.702$.

$$
\begin{gathered}
P B V=1.72-0.73 \beta+1.018 g+0.41 \text { PayR }+9.8 \text { ROE } \\
(9.43) \quad(-7.62) \quad(2.86) \quad(2.49)
\end{gathered}
$$

"Price/Sales" P/S multiple. $\mathrm{R}^{2}=0.589$.

$$
\begin{gathered}
P S=1.55-0.84 \beta+3.34 g+12.25 \text { Net } M \arg \text { in } \\
\quad(9.06) \quad(-8.62) \quad(9.08)
\end{gathered}
$$

EV/Invested Capital multiple. $\mathrm{R}^{2}=0.56$.

$$
\begin{aligned}
E V / \text { Invested Capital } & =2.58-6.21 \text { DebtR }+2.22 \mathrm{~g}+6.55 \text { ROIC } \\
& (10.48)(-10.26)
\end{aligned}
$$

EV/Sale multiple. $\mathrm{R}^{2}=0.55$. 


$$
\begin{aligned}
& E V / \text { Sale }= 2.94-2.52 \text { DebtR }+13.29 \text { OperM } \arg -6.93 \text { TaxRate } \\
&(13.92)(-6.50)
\end{aligned}
$$

EV/EBITDA multiple. $\mathrm{R}^{2}=0.44$.

$$
\begin{aligned}
E V / E B I T D A= & 19.44+24.86 g-17.53 \text { DebtR }-24.58 \text { TaxRate } \\
& (23.69)(14.43) \quad(-11.01)
\end{aligned}
$$

The values of coefficient of determination $-\mathrm{R}^{2}$ by given regressions are summarized in Table 3 .

Table 3. The values of the coefficient of determination by multiple regressions on Emerging Stock Markets

\begin{tabular}{lll}
\hline$\#$ & Multiple & $\mathrm{R}^{2}$ \\
\hline 1 & PBV & 0.702 \\
2 & PS & 0.589 \\
3 & EV/Invested Capital & 0.56 \\
4 & EV/Sale & 0.55 \\
5 & PEG & 0.508 \\
6 & PE & 0.47 \\
7 & EV/EBITDA & 0.44 \\
8 & PE FORVARD & 0.29 \\
\hline
\end{tabular}

Regressions of PBV, P/S, EV/Invested Capital multiples have the largest explanatory power for the sample of Emerging Markets. And P/E FORVARD, EV/EBITDA, PE multiples have the smallest explained variance.

The regression results for the technology sector of Emerging Markets gave the following results.

$\mathrm{P} / \mathrm{E}$ multiple. $\mathrm{R}^{2}=0.48$.

$$
\begin{gathered}
P E=0.60+115.73 g+11.05 \text { PayR } \\
(9.77) \quad(2.59)
\end{gathered}
$$

Forward P/E. $\mathrm{R}^{2}=0.48$.

$$
\begin{aligned}
P E_{\text {Forward }} & =19.49-3.40 \beta+42.61 g-26.47 R O E \\
(6.17) & (-2.55)
\end{aligned}
$$

PEG multiple. $\mathrm{R}^{2}=0.454$.

$$
\begin{aligned}
& P E G=0,615-1,20 \ln (g)-0,404 \beta-2,93 \text { ROE } \\
& (1,20) \quad(-5,66) \quad(-2,17) \quad(-2,54)
\end{aligned}
$$

"Price/Book" PBV multiple. $\mathrm{R}^{2}=0.69$.

$$
\begin{gathered}
P B V=0.96-0.75 \beta+8.31 g \quad+8.41 R O E \\
(2.07) \quad(-3.85) \quad(7.23) \quad(7.09)
\end{gathered}
$$

"Price/Sales" P/S multiple. $\mathrm{R}^{2}=0.767$.

$$
\begin{gathered}
P S=-1.718-0.79 \beta+12.04 g+32.51 \text { Net } M \text { arg } \text { in } \\
(-2.22) \quad(-2.4) \quad(6.22) \quad(12.47)
\end{gathered}
$$

EV/Invested Capital multiple. $\mathrm{R}^{2}=0.755$.

$$
\begin{aligned}
E V / \text { Invested Capital } & =-0.918-5.61 \text { DebtR }+10.11 g+14.00 \text { ROIC } \\
& (-1.106)
\end{aligned}
$$

EV/Sale multiple. $\mathrm{R}^{2}=0.606$. 


$$
\begin{aligned}
E V / \text { Sale }= & 3.31-5.59 \text { DebtR }+20.09 \text { OperM } \arg -10.22 \text { TaxRate } \\
& (3.80) \quad(-2.26)
\end{aligned}
$$

EV/EBITDA multiple. $\mathrm{R}^{2}=0.596$.

$$
\begin{aligned}
E V / E B I T D A= & 16.25+71.22 g-25.59 \text { Debt } R-48.35 \text { TaxRate } \\
& (4.77)(7.43) \quad(-3.18)
\end{aligned}
$$

The values of coefficient of determination - $R^{2}$ by given regressions are summarized in Table 4 .

Table 4. The values of the coefficient of determination by multiple regressions on the technology sector

\begin{tabular}{lll}
\hline$\#$ & Multiple & $\mathrm{R}^{2}$ \\
\hline 2 & PS & 0.767 \\
3 & EV/Invested Capital & 0.755 \\
1 & PBV & 0.69 \\
4 & EV/Sale & 0.606 \\
5 & PEG & 0.596 \\
7 & EV/EBITDA & 0.596 \\
6 & PE & 0.48 \\
8 & PE & 0.48 \\
\hline
\end{tabular}

This time the scale of coefficients of variation of determination became smaller. But the three leaders and laggards have remained the same with slight changes. Regressions of $\mathrm{P} / \mathrm{S}, \mathrm{EV} /$ Invested Capital, and PBV multiples have the greatest explanatory power for the sample in the technology sector of Emerging Markets. P/E FORVARD, $\mathrm{P} / \mathrm{E}$, and EV/EBITDA multiples have the lowest explained variance.

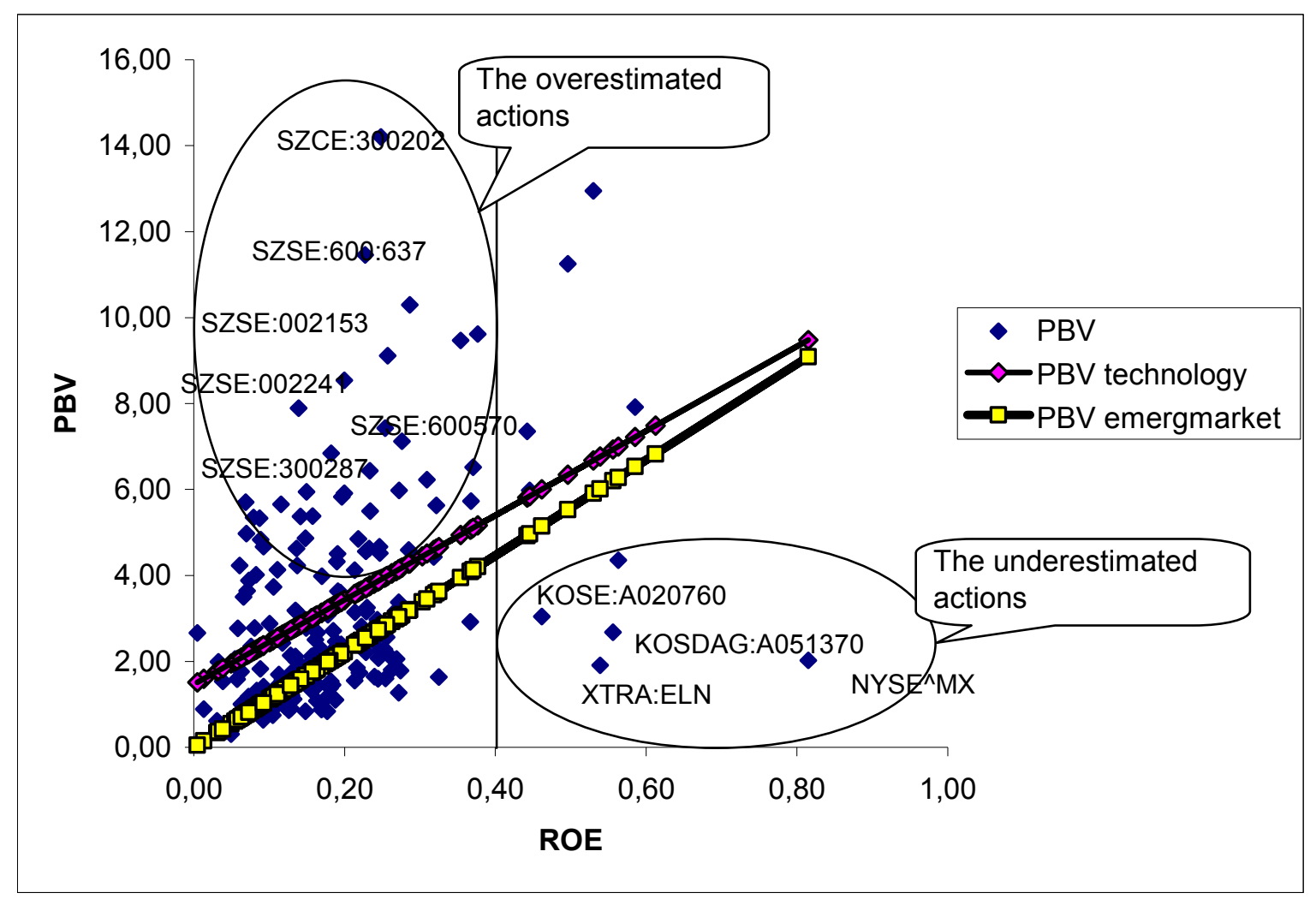

Figure 1. PBV multiple in relation with the return on equity (ROE) for the sample in the technology sector of Emerging Markets 
The three leading multiples of explained variance in regression were taken for the further analysis.

One of the purposes of multiples is the establishment of an undervaluation or overvaluation of stocks. Thus, the greater the multiple valuation is, the more it is overvalued, and the smaller it is, the more it is undervalued. In the case of regression of multiple, all values of multiples above regression will overvalued, and below - undervalued. However, as there are multiple regression and several fundamental factors, then their action can be multidirectional. In this case a matrix approach is recommended to be used. Consider PBV multiple. When using it, it is considered (Damodaran, 2012) that undervalued firms may be taken with low PBV multiples and a high return on equity (ROE). And accordingly, overvalued firms may be taken with high PBV and low ROE multiple.

Estimated values of PBV which were rebuilt on $\mathrm{ROE}$ were determined for submission of $\mathrm{PBV}=\mathrm{f}(\mathrm{ROE})$ to the sheet. The PBV analysis is shown in Figure 1.

The lower regression line belongs to the market in general, and the highest to the technology sector. That is the technology sector is a little overvalued relatively to the market as a whole. Overvalued stocks are in the top left quadrant, and undervalued stocks are in the lower right quadrant.

Net Profit Margin will be the driver for the P/S multiple. Applying the PS multiple, overvalued firms can be considered with the high PS multiple and low net profit margin. On the contrary, undervalued firms with high net profit margin and low PS multiple (Figure 2). The bottom line in Figure 2 is the regression of the market, and the top line is the regression of the technology sector.

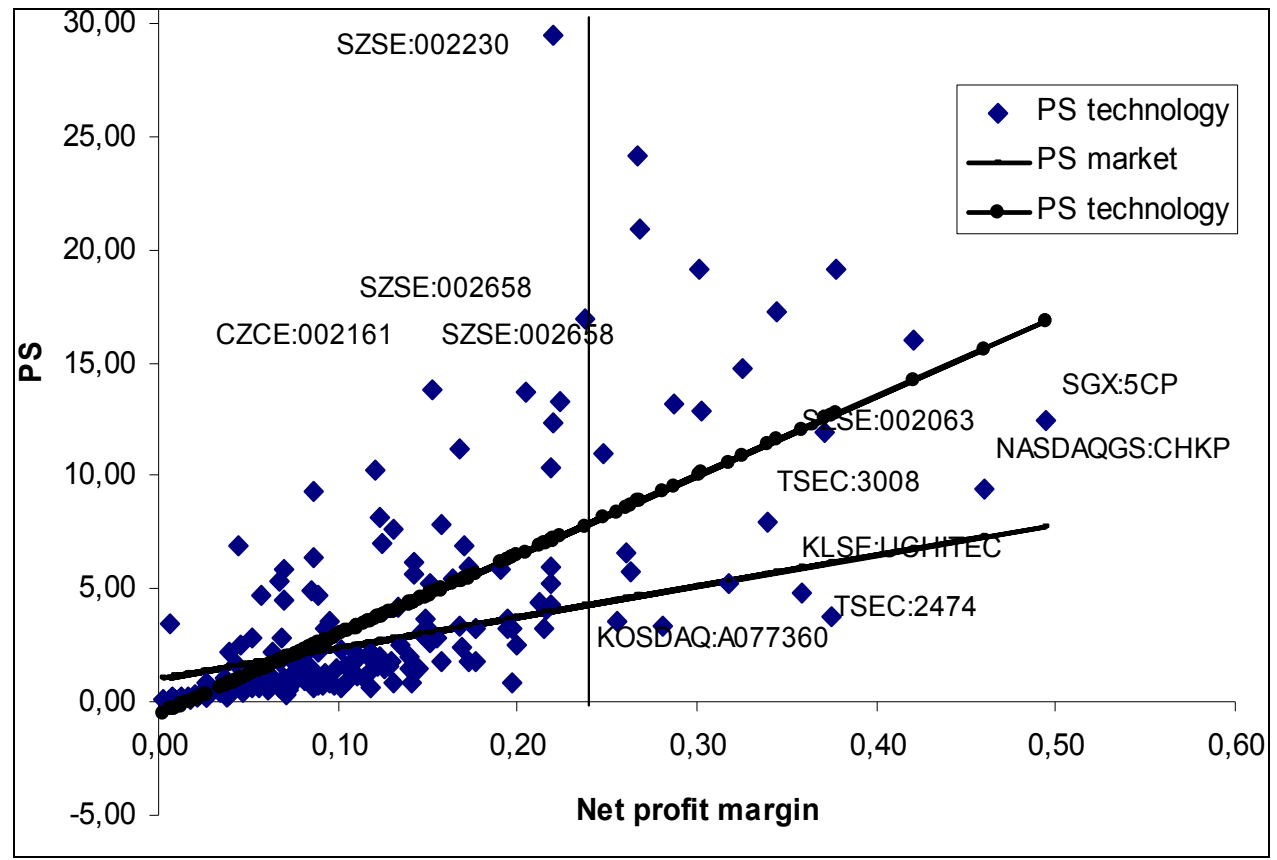

Figure 2. PS multiple in relation with net profit margin for the sample in the technology sector of Emerging Markets

Overvalued stocks are in the top left quadrant, and undervalued stocks are in the lower right quadrant.

Return on invested capital (ROIC) will be driver for the EV/Invested Capital multiple. Stocks of the company with high EV/Invested Capital multiples and low ROIC are overvalued, and with low EV/Invested Capital multiples and high ROIC are undervalued (Figure 3).

The lower regression line belongs to the market in general, and the highest to the technology sector. Overvalued stocks are in the top left quadrant, and undervalued stocks are in the lower right quadrant. 


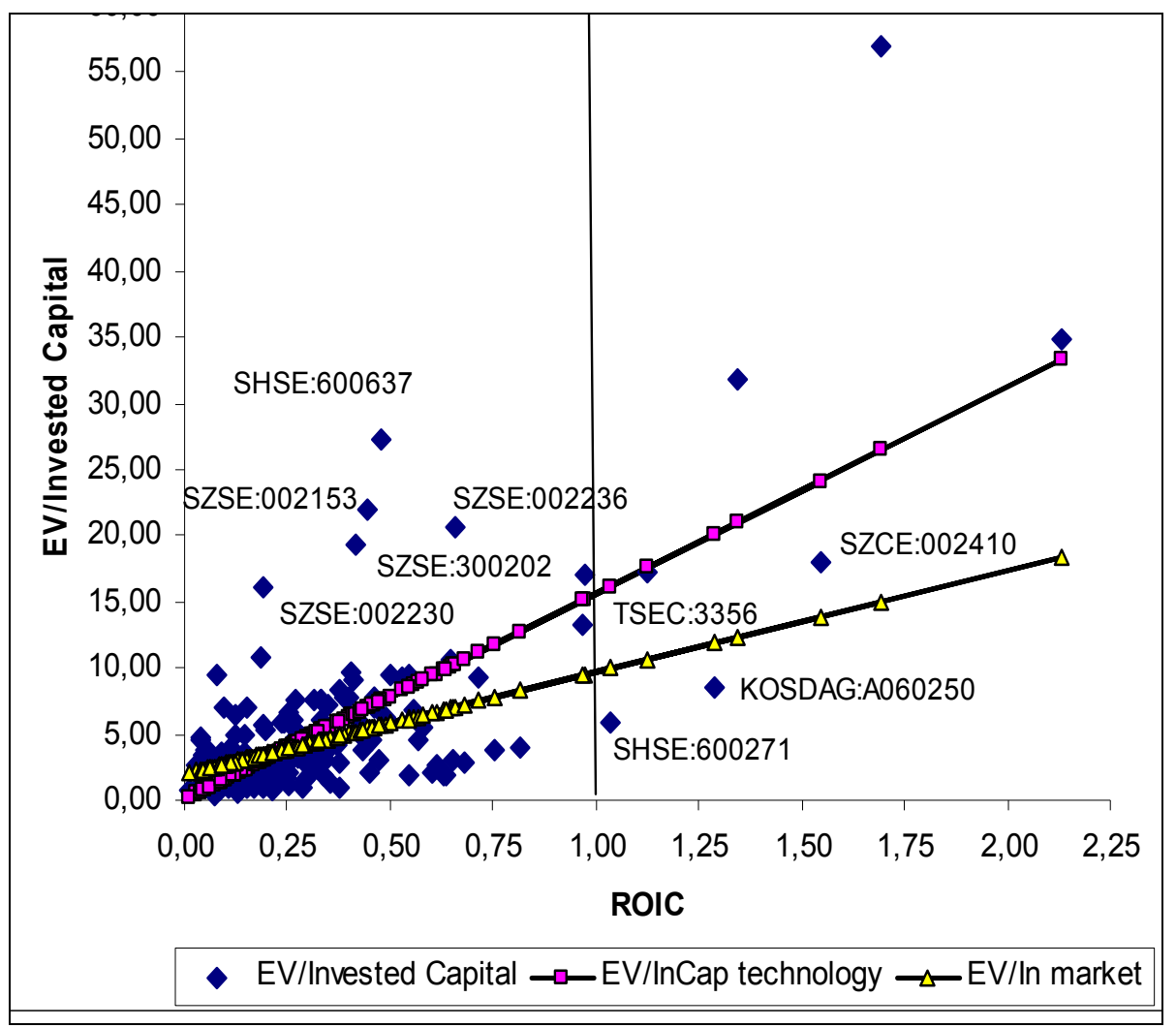

Figure 3. EV/Invested Capital multiple in relation with ROIC for the sample in the technology sector of Emerging Markets

\section{Discussion}

The most appropriate multiples for the technology sector of Emerging Markets were set in this article. The use of valuation in a particular sector of industry is a method of increasing the sample of comparable firms.

Regression approach was used, which could explain a large part of the difference between the multiples of different companies in a sector of industry. Ranking of multiples carried out on the accuracy and explanatory power of regressions. Regression analysis is a method to mitigate the differences between basic variables determining the multiples. The selection of basic variables was carried out by statistical criteria and correlate with the results of A. Damodaran (2012).

The studies of Harbula (2009), Damodaran (2012), Fernandez (2013) and others have noted the priority in the accuracy or explanatory power of the multiples. Specific results are different due to the sample firms, sector of industry, market and time of study.

It is obvious that the results obtained in terms of the values of the coefficients of regressions are variable in time. But rating of multiples on explanatory power is quite stable. This result can be improved by introducing additional covariates that characterize the country indicators, primarily GDP, interest rates, and sovereign risk.

A fact confirmed in this study is the availability of the most appropriate multiples for each sector, that is having a relatively better explanatory power installed on the appropriate regression of each multiple.

\section{Conclusions}

This article made a comparison of the entire list of multiples according to Emerging Markets data on 01.01.2013 with multiples of the technology sector, and the most suitable multiples for the technology sector are recommended according to the certain criteria.

It was found that Forward PE, EV/EBITDA, Current PE multiples have the lowest coefficient of variation throughout all Emerging Markets, and PEG, EV/EBIT, EV/Invested Capital multiples have the highest coefficient of variation. 
In the technology sector, Forward PE, PBV, Current PE have the lowest coefficient of variation, and EV/Invested Capital, PS, EV/Sales have the highest coefficient of variation.

Regressions of all multiples on the most significant basic variables were established in this study. Wherein regression dependencies differ in their statistical properties.

Regressions of PBV, PS, EV/Invested Capital multiples have the largest explanatory power for the sample of Emerging Markets. And PE FORVARD, EV/EBITDA, PE multiples have the smallest of explained variance.

Regression of the same PS, EV/Invested Capital, and PBV multiples have the greatest explanatory power for the sample of the technology sector of Emerging Markets. And PE FoRvard, PE, EV/EBITDA multiples have the smallest of explained variance. The analysis to identify undervalued/overvalued stocks of the technology sector was carried out for multiples - leaders on explained variance of PBV, PS, EV/Invested Capital.

Such an analysis can be applied to investment analysis. It allows mitigating the differences between growth, risk and cash flow, and identifying inconsistencies between ROE and PBV multiple, between net profit margin and PS multiple, between ROIC and EV/Invested Capital multiple. Additional covariates that characterize the country indicators can be entered for better results.

\section{References}

An, J., Bhojraj, S., \& Ng, D. (2010). Country. Industry and Idiosyncratic Components in Valuation Ratios. Working Paper. Korea Institute for International Economic Policy. Korea; Cornell University and the Wharton School at the University of Pennsylvania. U.S.A.

Bhojraj, S., \& Lee C. (2002). Who Is My Peer? A Valuation-Based Selection of Comparable Firms. Journal of Accounting Research, 40, 407-439. http://dx.doi.org/10.1111/1475-679X.00054

Cheng, C., \& McNamara, R. (2000). The valuation accuracy of the price earnings and price-book benchmark valuation methods. Review of Quantitative Finance and Accounting, 15, 349-370. http://dx.doi.org/ 10.1023/A:1012050524545

Cooper, I., \& Cordeiro, L. (2008, September 23). Optimal Equity Valuation Using Multiples: The Number of Comparable Firms. Retrieved November 30, 2014, from http://www.ssrn.com/abstract=1272349

Damodaran, A. (2009). Volatility Rules: Valuing Emerging Market Companies. Stern School of Business.

Damodaran, A. (2014, April). Retrieved April 1, 2014, from http://www.pages.stern.nyu.edu/ adamodar/

Damodaran, A., \& Damodaran, A. (2002. 2012). Investment Valuation - Tools and Techniques for Determining the Value of Any Asset (2nd ed., New York: J. Wiley and Sons; 3nd ed.; 3rd ed., Vol. 519, New York: J. Wiley and Sons).

Dittmann, I., \& Weiner, C. (2005). Selecting Comparable for the Valuation of Europeans Firms. Working Paper. Berlin: Humboldt University. Retrieved November 30, 2014, from http://www.econstor.eu/dspace/bitstream/ 10419/25021/1/495975710.PDF

Easton, P. (2004). PE Ratios. PEG Ratios and Estimating the Implied Expected Rate of Return on Equity Capital. Accounting Review, 79, 73-95. http://dx.doi.org/10.2308/accr.2004.79.1.73

Fernandez, P. (2013, November 4). Valuation Using Multiples: How Do Analysts Reach Their Conclusions? Retrieved November 30, 2014, from http://www.ssrn.com/abstract $=274972$

Foster, G., Kasznik, R., \& Sidhu, B. (2011, April). International Equity Valuation: The Relative Importance of Country and Industry Factors Vs. Company-Specific Financial Reporting Information. (Forthcoming in 2012: Accounting and Finance. Wiley-Blackwell).

Gaio, C. (2009). The Relative Importance of Firm and Country Characteristics for Earnings Quality Around the World. Working Paper, ISEC, Lisbon, Portugal.

Harbula, P. (2009, November 14). Valuation Multiples: Accuracy and Drivers - Evidence from the European Stock Market. Business Valuation Review, 4(28), 33.

Henschke, S., \& Homburg, C. (2009, May 15). Equity Valuation Using Multiples: Controlling for Differences between Firms. Retrieved November 30, 2014, from http://www.ssrn.com/abstract=1270812

Holthausen, R., \& Zmijewski, M. (2012). Valuation with Market Multiples: How to Avoid Pitfalls When Identifying and Using Comparable Companies. Journal of Applied Corporate Finance, 3(24), 26-38. http://dx.doi.org/10.1111/j.1745-6622.2012.00387.x 
Lie, E., \& Lie, H. (2002). Multiples used to estimate corporate value. Financial Analysts Journal, 58, 44-54. http://dx.doi.org/10.2469/faj.v58.n2.2522

Liu, J., Nissim, D., \& Thomas, J. (2002). Equity Valuation Using Multiples. Journal of Accounting Research, 40, 135-172. http://dx.doi.org/10.1111/1475-679X.00042

Liu, J., Nissim, D., \& Thomas, J. (2007). Is Cash Flow King in Valuations? Financial Analysts Journal, 2(63), 56-65. http://dx.doi.org/10.2469/faj.v63.n2.4522

Penman, S., \& Zhang, X. (2006, June 1). Modeling Sustainable Earnings and P/E Ratios with Financial Statement Analysis. Retrieved August 17, 2011, from http://www.ssrn.com/abstract=318967

Schreiner, A., \& Spremann, K. (2007, August 13). Multiples and Their Valuation Accuracy in European Equity Markets. Working Paper. Retrieved November 30, 2014, from http://www.ssrn.com/abstract $=957352$

Yee, K. (2004). Combining Value Estimates to Increase Accuracy. Financial Analysts Journal, 60, 23-28. http://dx.doi.org/10.2469/faj.v60.n4.2633

Yee, K. (2008). Bayesian framework for combining valuation estimates. Review of Quantitative Finance and Accounting, 30, 339-354. http://dx.doi.org/10.1007/s11156-007-0055-6

Yoo, Y. (2006). The Valuation Accuracy of Equity Valuation using a Combination of Multiples. Review of Accounting and Finance, 5, 108-123. http://dx.doi.org/10.1108/14757700610668958

\section{Copyrights}

Copyright for this article is retained by the author(s), with first publication rights granted to the journal.

This is an open-access article distributed under the terms and conditions of the Creative Commons Attribution license (http://creativecommons.org/licenses/by/3.0/). 